\title{
The impact of folate pathway polymorphisms combined to nutritional deficiency as a maternal predisposition factor for Down syndrome
}

\author{
C.B. Santos-Rebouças ${ }^{\mathrm{a}, *}$, J.C. Corrêa ${ }^{\mathrm{a}}$, A. Bonomo ${ }^{\mathrm{a}}$, N. Fintelman-Rodrigues ${ }^{\mathrm{a}}$, K.C.V. Moura $^{\mathrm{a}}$, \\ C.S.C. Rodrigues ${ }^{\mathrm{b}}$, J.M. Santos ${ }^{\mathrm{a}}$ and M.M.G. Pimentel ${ }^{\mathrm{a}}$ \\ ${ }^{a}$ Departamento de Genética, Universidade do Estado do Rio de Janeiro, Rio de Janeiro, Brazil \\ ${ }^{\mathrm{b}}$ Instituto de Nutrição, Universidade do Estado do Rio de Janeiro, Rio de Janeiro, Brazil
}

\begin{abstract}
Polymorphisms in genes encoding folate metabolizing enzymes have been linked to an increased risk of maternal chromosomal nondisjunction in several populations. With the purpose of evaluating this relationship, we compared the frequencies of $677 \mathrm{C}>\mathrm{T}$ and $1298 \mathrm{~A}>\mathrm{C}$ polymorphisms in the methylenetetrahydrofolate reductase gene $(M T H F R)$ and $66 \mathrm{~A}>\mathrm{G}$ in the methionine synthase reductase gene (MTRR) between 103 young mothers of Down syndrome (DS) individuals and 108 control mothers, whose offspring was karyotypically normal, correlating it with an estimative of folate and - related micronutrients levels intake. Maternal and paternal transmission frequencies of MTHFR 677T allele were also examined to access potential parentof-origin effects. PCR-RFLP for genomic DNA was accomplished and allele/genotype frequencies differences were determined using the $\mathrm{x}^{2}$ test, whereas pattern of transmission of the MTHFR 677 allele was analyzed by transmission disequilibrium test. None of the polymorphisms seemed to be more frequent in case mothers than in controls, either individually or combined. The estimative of nutritional intake revealed that folate consumption median was inadequate in both groups, whereas methionine and zinc consumption medians were significantly greater in control mothers. It suggests that such interaction between genetic profile and environment could predispose this sub group of women to have a DS child. Additional studies focusing the interaction between nutritional intakes, biochemical data and folate pathway polymorphisms are needed to confirm the present results. The possibility of neutralize the biochemical negative effects of folate-related polymorphisms through oral supplementation could provide new targets for DS prevention.
\end{abstract}

Keywords: Down syndrome, trisomy 21, folate, homocysteine, MTHFR

\section{Introduction}

DNA methylation plays a key role in several human biological processes, including spacial/temporal gene regulation and centromeric stability [29]. The dona-

* Corresponding author: Dr. C.B. Santos-Rebouças, Universidade do Estado do Rio de Janeiro, Instituto de Biologia Roberto Alcântara Gomes, Departamento de Genética, Serviço de Genética Humana, Rua São Francisco Xavier, 524, PHLC - sala 500, Maracanã 20550013, Rio de Janeiro, RJ, Brasil. Tel.: +55 212587 7107; Fax: +55 212587 7377; E-mail: cbs@uerj.br. tion of carbon atoms for maintenance of DNA methylation patterns is mainly realized through the folate pathway, which involves an integrated action of many gene products and other important micronutrients also obtained by dietary, like vitamin B12, vitamin B6, zinc and methionine. All these elements are directly or indirectly required for the conversion of homocysteine to methionine, which is the immediate precursor of S-adenosyl methionine (SAM), the major intracellular methyl donor. Impairments in folate metabolism result in impaired chromosomal segregation due to hy- 
pomethylation of heterochromatin causing structural centromere defects that could induce abnormal distribution of replicated chromosomes during nuclear division [40]. Maternal polymorphisms that alter the functionality of key molecules required for the folate pathway steps, associated with a low folate intake during pre conceptional, have been proposed to contribute to Down syndrome (DS) in the fetus [20].

In $95 \%$ of DS cases, the nondisjunction of chromosome 21 occurs during meiosis I in the maturing oocyte and although advanced maternal age still represents the major risk factor for DS, most children with this complex metabolic disease are born from young mothers (less than 35 years) [12]. The most common folate pathway genes studied in different populations include the methylenetetrahydrofolate reductase gene (MTHFR), whose product catalyzes the synthesis of methyltetrahydrofolate, the methyl donor of homocysteine, and methionine sintase reductase gene (MTRR), which codifies an enzyme that reduces the cobalt of cobalamin, maintaining methionine sintase in an active state and making possible the folate- and vitamin $\mathrm{B}_{12}$ dependent synthesis of methionine by remethylation of homocysteine.

We investigated the relationship of $M T H F R 677 \mathrm{C}>\mathrm{T}$, MTHFR $1298 \mathrm{~A}>\mathrm{C}$ and MTRR $66 \mathrm{~A}>\mathrm{G}$ polymorphisms on the risk of having a DS child in association with an estimative of folate and -related micronutrients levels intake. The transmission pattern of the parental $M T H-$ $F R$ 677T allele to the DS child was also evaluated.

\section{Subjects and methods}

After excluding non-meiotic genetic causes of DS (Robertsonian translocations, mosaicism, complex rearrangements), 103 mothers (18-35 years during conception) of full trisomy 21 children were ascertained from the Human Genetic Service of State University of Rio de Janeiro (Brazil). For comparative purposes, 108 age-matched mothers who had normal chromosomes children and no history of abnormal pregnancies or miscarriages were also recruited. The selected DS and control mothers have similar social-economic patterns and resided in the same geographic area in Rio de Janeiro, Brazil. For parental MTHFR 677T transmission, 47 triad comprising mother-father-DS child were also examined. All the research protocols were previously approved by the regional Ethic's Committee.

Genomic DNA was isolated from peripheral blood by GFX Genomic Blood DNA purification Kit (GE-
Healthcare) and analyzed by PCR-RFLP. For MTHFR 677 genotype analysis, conditions were performed according to Chen et al. [8], whereas for MTHFR 1298 and MTRR 66 genotypes analysis were used the protocols described by van der Put et al. [38] and Wilson et al. [41], respectively. The digested PCR products were visualized by $8-10 \%$ non-denaturing polyacrylamide stained by silver (Fig. 1). Samples from homozygous and heterozygous individuals, whose genotypes have been previously established, were included in all procedures to serve as controls.

A previously validated food-frequency questionnaire [33] was filled out by the mothers to estimate the consumption of folate and other related micronutrients (methionine, zinc, vitamins $\mathrm{B}_{6}$ and $\mathrm{B}_{12}$ ). NutWin software (version 1.5.2, UNIFESP/São Paulo, Brazil) was used to analyze dietary intake data and comparisons between groups were evaluated with the Mann Whitney U-test.

Statistical comparisons were performed using the Instat Graph Pad Software (version 3.0, San Diego, USA). Allele frequencies were calculated for each genotype and the differences between case and control mothers were determined using the $\mathrm{x}^{2}$ test. Odds ratios were calculated for each genotype separately and for potential intragenic or gene-gene interactions. For MTHFR 677 parental transmission analysis, the transmission disequilibrium test (TDT) was applied [34] to determine if specific alleles were transmitted more frequently than the expected from heterozygous parents to the affected offspring (50\% according to the Mendelian inheritance ratios).

\section{Results}

There were no significant differences between groups in terms of mean age at conception (28.36 \pm 6.06 years for DS mothers versus $29.54 \pm 5.6$ years for control mothers), ethnicity and socioeconomic status. The distributions of the MTHFR and MTRR genotypes in both populations were found to be in HardyWeinberg equilibrium. Table 1 indicates the $M T H$ $F R$ and MTRR genotypic frequencies. The frequencies of the MTHFR 677CC and 1298AA wild-type genotypes were higher in both the case and control mothers, whereas MTRR 66AG heterozygous genotype was the preponderant in both groups. Frequencies of $M T H$ $F R$ 677C $>$ T, MTHFR $1298 \mathrm{~A}>\mathrm{C}$ and MTRR 66A $>\mathrm{G}$ genotypes were similar among DS and control groups, even in the combination of heterozygous and homozy- 

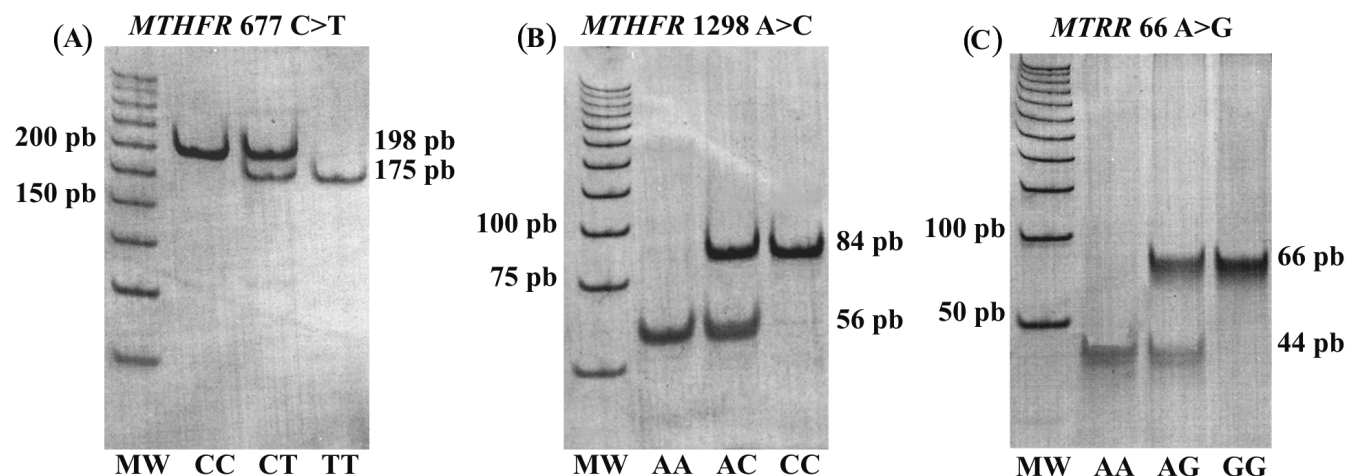

Fig. 1. Polyacrilamide gel electrophoresis for analysis of the MTHFR $677 \mathrm{C}>\mathrm{T}, M T H F R$ 1298A $>\mathrm{C}$ and $M T R R 66 \mathrm{~A}>\mathrm{G}$ polymorphisms after PCR-RFLP procedure. Lane 1 in all gels represents the molecular weight marker. (A) Different products for MTHFR 677 C $>$ T polymorphism. Lane 2: homozygous CC with doublet band at 198 bp; Lane 3: 198 and 175 bp bands from a heterozygous CT; Lane 4: homozygous TT which displays doublet band at $175 \mathrm{bp}$. (B) Different products for MTHFR $1298 \mathrm{~A}>\mathrm{C}$ polymorphism. Lane 2: homozygous AA with two bands at $56 \mathrm{bp}$; Lane 3: 84 and 56 bp bands from a heterozygous AC individual; Lane 4: homozygous CC which displays a doublet band at $84 \mathrm{bp}$. (C) Different products for MTRR 66A $>$ G polymorphism. Lane 2: homozygous AA with a doublet band at 44 bp; Lane 3: 66 bp and 44 bp bands from a heterozygous AG individual; Lane 4: homozygous GG which displays doublet band at $66 \mathrm{bp}$.

Table 1

Genotypic frequencies, odds ratios and $\mathrm{p}$ value of MTHFR $(677 \mathrm{C}>\mathrm{T}$ and $1298 \mathrm{~A}>\mathrm{C})$ and $M T R R$ $(66 \mathrm{~A}>\mathrm{G})$ polymorphisms in case and control mothers

\begin{tabular}{|c|c|c|c|c|}
\hline Polymorphism & Genotype & $\begin{array}{c}\text { Control mothers } \\
(n=108) \\
n[\%]\end{array}$ & $\begin{array}{c}\text { Case mothers } \\
(n=103) \\
n[\%]\end{array}$ & $\begin{array}{l}\text { Odds ratio } \\
\text { (IC 95\%) }\end{array}$ \\
\hline \multirow[t]{5}{*}{ MTHFR $677 \mathrm{C}>\mathrm{T}$} & $\mathrm{CC}$ & $49[45.4]$ & $51[49.5]$ & $\begin{array}{l}1.0 \\
\text { reference }\end{array}$ \\
\hline & $\mathrm{CT}$ & $47[43.5]$ & $43[41.8]$ & $\begin{array}{l}0.88(0.49-1.55) \\
p=0.66\end{array}$ \\
\hline & $\mathrm{TT}$ & 12 [11.1] & 9 [8.7] & $\begin{array}{l}0.72(0.28-1.86) \\
p=0.63\end{array}$ \\
\hline & $\mathrm{CT}+\mathrm{TT}$ & $59[54.6]$ & $52[50.5]$ & $\begin{array}{l}0.58(0.49-1.45) \\
p=0.58\end{array}$ \\
\hline & Frequency of $\mathrm{T}$ & 0.32 & 0.29 & - \\
\hline \multirow[t]{5}{*}{$M T H F R$ 1298A $>C$} & $\mathrm{AA}$ & $57[52.8]$ & $58[56.3]$ & $\begin{array}{l}1.0 \\
\text { reference }\end{array}$ \\
\hline & $\mathrm{AC}$ & $49[45.4]$ & 40 [38.9] & $\begin{array}{l}0.80(0.46-1.40) \\
p=0.48\end{array}$ \\
\hline & $\mathrm{CC}$ & $2[1.8]$ & $5[4.8]$ & $\begin{array}{l}0.44(0.46-13.20) \\
p=0.44\end{array}$ \\
\hline & $\mathrm{AC}+\mathrm{CC}$ & $51[47.2]$ & 45 [43.7] & $\begin{array}{l}0.87(0.50-1.49) \\
p=0.87\end{array}$ \\
\hline & Frequency of C & 0.24 & 0.24 & - \\
\hline \multirow[t]{5}{*}{$M T R R 66 \mathrm{~A}>\mathrm{G}$} & AA & 31 [28.7] & 39 [37.9] & $\begin{array}{l}1.0 \\
\text { reference }\end{array}$ \\
\hline & $\mathrm{AG}$ & $49[45.4]$ & $44[42.7]$ & $\begin{array}{l}0.71(0.38-1.33) \\
p=0.34\end{array}$ \\
\hline & GG & 28 [25.9] & $20[19.4]$ & $\begin{array}{l}0.56(0.27-1.19) \\
p=0.19\end{array}$ \\
\hline & $\mathrm{AG}+\mathrm{GG}$ & 77 [71.3] & $64[62.1]$ & $\begin{array}{l}0.66(0.37-1.18) \\
p=0.19\end{array}$ \\
\hline & Frequency of $\mathrm{G}$ & 0.49 & 0.41 & - \\
\hline
\end{tabular}

gous variant genotypes. Furthermore, the multiplicative interaction analysis between the studied polymorphisms showed also no significant evidence for association (Table 2). The median number of polymorphic alleles for the three tested polymorphisms between case and controls also did not reach significant differences $(p=0.25)$.

Amongst the 47 triads investigated for the parental 
Table 2

Analysis of multiplicative interaction between MTHFR $(677 \mathrm{C}>\mathrm{T}$ and $1298 \mathrm{~A}>\mathrm{C})$ and $M T R R$ $(66 \mathrm{~A}>\mathrm{G})$ polymorphisms in case and control mothers, odd ratios and $\mathrm{p}$ values

\begin{tabular}{|c|c|c|c|c|c|}
\hline $\begin{array}{l}\text { Combination of } \\
\text { genotypes }\end{array}$ & $\begin{array}{c}\text { Control mothers } \\
(n=108)\end{array}$ & $\begin{array}{c}\text { Case mothers } \\
(n=103)\end{array}$ & $\overline{\mathrm{OR}}$ & CI 95\% & $p$ \\
\hline \multicolumn{6}{|l|}{ MTHFR677 / MTHFR 1298} \\
\hline $677 \mathrm{CC} / 1298 \mathrm{AA}$ & 23 & 20 & - & reference & - \\
\hline 677CT/1298AA & 23 & 29 & 1.45 & $0.64-3.26$ & 0.41 \\
\hline 677TT/1298AA & 11 & 9 & 0.94 & $0.32-2.73$ & 1.00 \\
\hline $677 \mathrm{CT}+\mathrm{TT} / 1298 \mathrm{AA}$ & 34 & 38 & 1.28 & $0.60-2.74$ & 0.56 \\
\hline $677 \mathrm{CC} / 1298 \mathrm{AC}$ & 24 & 26 & 1.24 & $0.55-2.82$ & 0.68 \\
\hline $677 \mathrm{CT} / 1298 \mathrm{AC}$ & 24 & 14 & 0.67 & $0.27-1.63$ & 0.49 \\
\hline 677TT/1298AC & 1 & 0 & 0.38 & $0.01-9.91$ & 1.00 \\
\hline $677 \mathrm{CC} / 1298 \mathrm{AC}+\mathrm{CC}$ & 26 & 31 & 1.37 & $0.62-3.03$ & 0.54 \\
\hline $677 \mathrm{CC} / 1298 \mathrm{CC}$ & 2 & 5 & 2.87 & $0.50-16.48$ & 0.42 \\
\hline $677 \mathrm{CT} / 1298 \mathrm{CC}$ & 0 & 0 & - & - & - \\
\hline $677 \mathrm{TT} / 1298 \mathrm{CC}$ & 0 & 0 & - & - & - \\
\hline $677 \mathrm{CT}+\mathrm{TT} / 1298 \mathrm{AC}+\mathrm{CC}$ & 25 & 14 & 0.64 & $0.26-1.56$ & 0.37 \\
\hline \multicolumn{6}{|l|}{ MTHFR677 / MTRR66 } \\
\hline 677CC/66AA & 14 & 19 & _- & reference & - \\
\hline 677CT/66AA & 12 & 17 & 1.04 & $0.38-2.87$ & 1.00 \\
\hline 677TT/66AA & 5 & 3 & 0.44 & $0.09-2.16$ & 0.43 \\
\hline $677 \mathrm{CT}+\mathrm{TT} / 66 \mathrm{AA}$ & 17 & 20 & 0.86 & $0.33-2.23$ & 0.81 \\
\hline $677 \mathrm{CC} / 66 \mathrm{AG}$ & 22 & 21 & 0.70 & $0.28-1.75$ & 0.49 \\
\hline $677 \mathrm{CT} / 66 \mathrm{AG}$ & 23 & 20 & 0.64 & $0.25-1.60$ & 0.36 \\
\hline 677TT/66AG & 4 & 3 & 0.55 & $0.10-2.87$ & 0.68 \\
\hline $677 \mathrm{CC} / 66 \mathrm{AG}+\mathrm{GG}$ & 33 & 32 & 0.71 & $0.30-1.66$ & 0.52 \\
\hline $677 \mathrm{CC} / 66 \mathrm{GG}$ & 13 & 11 & 0.62 & $0.22-1.80$ & 0.43 \\
\hline 677CT/66GG & 12 & 6 & 0.37 & $0.11-1.22$ & 0.14 \\
\hline 677TT/66GG & 3 & 3 & 0.74 & $0.12-4.21$ & 1.00 \\
\hline $677 \mathrm{CT}+\mathrm{TT} / 66 \mathrm{AG}+\mathrm{GG}$ & 42 & 32 & 0.56 & $0.25-1.29$ & 0.21 \\
\hline \multicolumn{6}{|l|}{ MTHFR 1298 / MTRR 66} \\
\hline 1298AA/66AA & 15 & 25 & - & reference & - \\
\hline 1298AC/66AA & 16 & 13 & 0.48 & $0.18-1.29$ & 0.22 \\
\hline 1298CC/66AA & 0 & 1 & 1.82 & $0.07-47.64$ & 1.00 \\
\hline $1298 \mathrm{AC}+\mathrm{CC} / 66 \mathrm{AA}$ & 16 & 14 & 0.52 & $020-1.37$ & 0.22 \\
\hline 1298AA/66AG & 28 & 22 & 0.47 & $0.20-1.10$ & 0.09 \\
\hline $1298 \mathrm{AC} / 66 \mathrm{AG}$ & 20 & 19 & 0.57 & $0.23-1.39$ & 0.26 \\
\hline $1298 \mathrm{CC} / 66 \mathrm{AG}$ & 1 & 3 & 1.80 & $0.17-18.92$ & 1.00 \\
\hline 1298AA/66AG+GG & 42 & 33 & 0.47 & $0.21-1.03$ & 0.07 \\
\hline 1298AA/66GG & 14 & 11 & 0.47 & $0.17-1.30$ & 0.20 \\
\hline 1298AC/66GG & 13 & 8 & 0.37 & $0.12-1.09$ & 0.10 \\
\hline $1298 \mathrm{CC} / 66 \mathrm{GG}$ & 1 & 1 & 0.60 & $0.03-10.32$ & 1.0 \\
\hline $1298 \mathrm{AC}+\mathrm{CC} / 66 \mathrm{AG}+\mathrm{GG}$ & 35 & 31 & 0.53 & $0.24-1.18$ & 0.16 \\
\hline
\end{tabular}

transmission of the MTHFR $677 \mathrm{~T}$ allele, four were uninformative, since the parents and the DS offspring were heterozygous, making the determination of the parental origin impossible. There was a trend to the transmission of $\mathrm{T}$ allele in the marriage among heterozygous parents (CT/CT), resulting in an offspring with $44.4 \%$ of the DS children with genotype CT and $55.6 \%$ with genotype TT, while the expected genotypes distribution in agreement with the Mendelian basis should be $25 \%$ of CC, $50 \%$ of CT and $25 \%$ of TT (Table 3). Moreover, among marriages between fathers with CT genotype and mothers with CC genotype, there was a little increase in the expected CT genotype in DS children (Table 3). The parental origin of the $\mathrm{T}$ allele could be determined for 33 of the 47 triads. In the offspring of heterozygous mothers, there was not a preferential transmission of maternal allele $\mathrm{T}$ ( $p=$ 0.62 ), whereas inheritance of $\mathrm{T}$ allele from heterozygous fathers to affected offspring was more than three times increased than expected by chance $(p=0.03)$ (Table 4). When the frequencies of maternal and paternal transmission were taken together, the $\mathrm{T}$ allele was transmitted 22 times $(66.7 \%)$, while the $\mathrm{C}$ allele was transmitted 11 times $(33.3 \%)$. These results suggest that there was not significant statistical evidence that $\mathrm{T}$ allele has been transmitted more than expected according to Mendelian segregation.

Regarding the nutritional analysis, it was found that 
Table 3

MTHFR 677C $>$ T genotypes and expected genotypes (according to Mendelian inheritance) of parents and DS offspring in family triads

\begin{tabular}{|c|c|c|c|c|}
\hline \multirow[t]{2}{*}{ Maternal / Paternal genotypes } & \multicolumn{3}{|c|}{ Genotypes of DS child (expected genotypes) } & \multirow{2}{*}{$\begin{array}{l}\text { Number of } \\
\text { offspring }\end{array}$} \\
\hline & $\mathrm{CC}$ & $\mathrm{CT}$ & TT & \\
\hline $\mathrm{CC} / \mathrm{CC}$ & $13(13.0)$ & - & - & 13 \\
\hline $\mathrm{CC} / \mathrm{CT}$ & $4(5.5)$ & $7(5.5)$ & - & 11 \\
\hline $\mathrm{CC} / \mathrm{TT}$ & - & $1(1.0)$ & - & 1 \\
\hline $\mathrm{CT} / \mathrm{CC}$ & $6(4.5)$ & $3(4.5)$ & - & 9 \\
\hline $\mathrm{CT} / \mathrm{CT}$ & - & $4(4.5)$ & $5(2.25)$ & 9 \\
\hline $\mathrm{CT} / \mathrm{TT}$ & - & $1(1.0)$ & $1(1.0)$ & 2 \\
\hline $\mathrm{TT} / \mathrm{CC}$ & - & $1(1.0)$ & - & 1 \\
\hline $\mathrm{TT} / \mathrm{CT}$ & - & $-(0.5)$ & $1(0.5)$ & 1 \\
\hline TT/TT & - & - & - & - \\
\hline Total & $23(46.4 \%)$ & $17(40.2 \%)$ & $7(13.4 \%)$ & $47(100 \%)$ \\
\hline
\end{tabular}

- Not observed.

Table 4

Frequencies of MTHFR 677C and 677T alleles transmission from heterozygous parents to DS offspring

\begin{tabular}{|c|c|c|c|c|c|c|}
\hline \multirow[t]{2}{*}{$\begin{array}{l}\text { Heterozygous } \\
\text { parents }(n)\end{array}$} & \multicolumn{2}{|c|}{$\begin{array}{l}\text { Transmission of } \\
677 \mathrm{C} \text { allele }(\%)\end{array}$} & \multicolumn{2}{|c|}{$\begin{array}{l}\text { Transmission of } \\
677 \mathrm{~T} \text { allele }(\%)\end{array}$} & \multicolumn{2}{|c|}{$\begin{array}{c}\text { McNemar } \\
\text { test }\end{array}$} \\
\hline & observed & expected & observed & expected & $\chi^{2}$ & $\mathrm{P}$ \\
\hline mother (16) & $7(43.7)$ & $8(50.0)$ & $9(56.3)$ & $8(50)$ & 0.25 & 0.62 \\
\hline father (17) & $4(23.5)$ & $8.5(50)$ & $13(76.5)$ & $8.5(50)$ & 4.76 & 0.03 \\
\hline Total (33) & $11(33.3)$ & $16.5(50)$ & $22(66.7)$ & $16.5(50)$ & 3.66 & 0.05 \\
\hline
\end{tabular}

Table 5

Estimative medians of folate, vitamin $\mathrm{B}_{12}$, vitamin $\mathrm{B}_{6}$, zinc and methionine intakes at the preconceptional moment and $\mathrm{p}$ values in mothers of children with DS and controls

\begin{tabular}{lcccc}
\hline Micronutrient & $\begin{array}{c}\text { Dietary reference } \\
\text { intakes* }^{*}\end{array}$ & Case mothers & Control mothers & $p$ value \\
\cline { 2 - 5 } & 400 & $224.28 \pm 100.66$ & $216.70 \pm 62.45$ & 0.82 \\
Folate $(\mu \mathrm{g} /$ day $)$ & 2.4 & $5.46 \pm 13.74$ & $8.86 \pm 8.55$ & 0.07 \\
Vitamin $\mathrm{B}_{12}(\mu \mathrm{g} /$ day $)$ & 1.3 & $1.61 \pm 0.95$ & $1.85 \pm 0.66$ & 0.38 \\
Vitamin $\mathrm{B}_{6}(\mathrm{mg} /$ day $)$ & 8.0 & $0.6 \pm 1.93$ & $4.57 \pm 1.26$ & $<0.0001$ \\
Zinc $(\mathrm{mg} /$ day) & 0.8 & $0.06 \pm 0.37$ & $0.79 \pm 0.20$ & $<0.0001$ \\
Methionine (mg/day) & &
\end{tabular}

*According to Dietary Reference Intakes [11].

the intake of folate in both groups was insufficient in comparison to the recommended value of Dietary Reference Intake (Table 5) [11]. Although the ingestion of zinc was significantly greater in the control sample, the intake median values in both groups was inadequate in comparison to the recommended value. Concerning the estimative consumption of methionine, it was observed that there was a significantly greater ingestion of this micronutrient among the controls in comparison with DS mothers, but only the latter presented lower value than the reference. For the vitamins B6 and B12 consumption, there were no differences between the samples and the medians of intake were in agreement with the recommended reference. All mothers ascertained in this study related that they were not under a particular dietary supplemented by folate before conception.

\section{Discussion}

Contradictory findings from a number of different geographic populations have been published on the evaluation of folate pathway polymorphisms as a risk for having a DS child. Our results corroborates the general profile of genotype frequencies reported in a recent meta-analysis of 11 eligible case-control studies [42], in which the genotypes MTHFR 677CC and $677 \mathrm{CT}$ were the highest common in both case and control, similarly to those observed for genotypes $M T H F R$ 1298 AA and 1298 AC, whereas the MTRR 6AG genotype had the highest frequency for the polymorphism MTRR 66A > G. Nevertheless, we did not support an independent or combined association of maternal $M T H$ FR 677T, MTHFR 1298C and MTRR 66G alleles to an increase risk of DS birth. 
Regarding the MTHFR $677 \mathrm{C}>\mathrm{T}$ polymorphism, some other studies did not found an independent association of maternal MTHFR $677 \mathrm{~T}$ allele to trisomy 21 [2-6,9,26,30,36,37]. In Mediterranean countries, like Italy and France, and in Japan such inexistence of an independent link between maternal MTHFR 677T allele and DS has been explained by a high intake of folate food, which could neutralize the negative biochemical effects of the polymorphism [6,9,37]. On the other hand, association of MTHFR 677T allele to DS was seen in North American [18,20], South American [1, 10], Asiatic [28,39] and Egyptian [23]. Furthermore, in some studies, the presence of the MTHFR 677 T combined to other alleles such as MTHFR $1298 \mathrm{C}$ [1,15,28, 30], MTRR 66G [18,40] or RFC-1 80G [9] increased the risk of DS.

In our MTHFR 677 transmission frequencies analysis, the $\mathrm{T}$ allele was transmitted from heterozygous fathers at a higher rate than expected by chance, but this preferentially transmission was not observed from the heterozygous mothers. Concerning that only parents with live DS infants were recruited in our study, these results corroborate those found by Hobbs et al. [17] and Rai et al. [28], suggesting a possible survival advantage of paternal $\mathrm{T}$ allele in DS live-born children, mainly in those, whose mothers are homozygous for $\mathrm{C}$ allele. This survival hypothesis points to a metabolic advantage associated to specific maternal/fetal $M T H$ $F R$ genotype interaction and the overexpression of cystathionine beta sinthase (CBS) gene in DS infants [17]. While MTHFR $677 \mathrm{~T}$ allele is associated with increased homocysteine in mothers of children with DS [20], low homocysteine levels are caused by CBS overexpression in DS infants. In children with DS, the upregulated CBS activity is due to the presence of three copies of this gene, which is located on chromosome 21. CBS functions to permanently remove homocysteine from the methionine cycle in a one-way reaction. The resulting increased catabolism of homocysteine leads to decreased synthesis of metabolically active tetrahydrofolate and methionine required for normal fetal growth and development. It was postulated that low homocysteine levels in the DS-affected fetus could be partially compensated in utero by the relatively high maternal plasma homocysteine that is associated with the $M T H$ FR 677 T allele in the mother [17]. Besides, increased homocysteine levels in mothers carrying $\mathrm{T}$ allele diminish the necessity of maternal $\mathrm{T}$ allele transmission for DS child survival, whereas paternal $\mathrm{T}$ allele transmission is required for fetal survival when the mother is homozygous for the $\mathrm{C}$ allele. By this way, trisomy 21 might be associated to one-carbon metabolism either in the production of methyl groups by altering the recombination/segregation of chromosome 21 and in the rate of survival of a DS child by the interaction between maternal/fetal genotypes.

For the MTHFR $1298 \mathrm{~A}>\mathrm{C}$ polymorphism, five studies showed an elevated risk for DS in the presence of the allele MTHFR 1298 C [15,22,23,28,30]. However, the association of this polymorphism with trisomy 21 was not confirmed by others $[1,3,6,9,10]$. In the interactive analysis between positions 677 and 1298 of MTHFR, it was found that there were no $677 \mathrm{CT} / 1298 \mathrm{CC}$ and 677 TT/1298 CC combinations, neither in controls or in DS mothers, pointing to a linkage disequilibrium between $677 \mathrm{C}>\mathrm{T}$ and $1298 \mathrm{~A}>\mathrm{C}$ polymorphisms as previously reported $[9,10,35,38]$. However, it seems that the linkage disequilibrium between $677 \mathrm{C}>\mathrm{T}$ and $1298 \mathrm{~A}>\mathrm{C}$ polymorphisms is not complete, since we have found one control individual with the 677TT/1298AC genotypes and the MTHFR $677 \mathrm{~T} / 1298 \mathrm{C}$ haplotype was also present in European samples [30], proving that this combination is rare and the two alleles have been separated along evolution [27,32].

Concerning the MTRR $66 \mathrm{~A}>\mathrm{G}$ polymorphism, the number of studies are more limited, but some of them evaluating USA-Canadian, Irish, Brazilian and Chinese populations $[1,18,26,40]$ found an association between the MTRR $66 \mathrm{G}$ and DS, mainly when this variant was associated to the MTHFR 677 T allele.

In Brazil, four previous studies accomplished in São Paulo city focused the problematic of maternal folate pathway polymorphisms and risk of DS $[1,2,10,15]$. In a preliminary report, Grillo and colleagues [15] found an independent and combined role of MTHFR $677 \mathrm{~T}$ and MTHFR $1298 \mathrm{C}$ alleles with DS, using a limited number of case mothers. After, Acacio and colleagues [1] demonstrated a multiplicative interaction between $677 \mathrm{CT}$ and $1298 \mathrm{AC}$ genotypes in increasing the risk of DS, even though they failed to found an isolated influence of these alleles in DS. Da Silva and colleagues [10] and Biselli and colleagues [2] extended the number of studied polymorphisms to other folaterelated genes and showed a higher median number of polymorphic alleles in DS mothers compared to controls, but only da Silva et al. [10] found an independent association of folate polymorphisms (MTHFR 677T) to DS. Although the allelic frequencies found by ours are similar to those seen in the two larger Brazilian studies [2,10], we did not support the evidence of a greater number of polymorphic alleles per individual in our case mothers from Rio de Janeiro city. However, 
it must be also emphasized that, in countries of continental size, such as Brazil, population genetic background and nutritional habits can differ among different regions. Besides, the studies of da Silva et al. [10] and Biselli et al. [2] included women over 35 years-old, which can be by itself a potential risk factor of having a DS child due to oocyte aging.

According to our nutritional estimative, Brazilian women at reproductive age have an unsatisfactory ingestion of folate (93.7\% of inadequate intake). Such results corroborate the study of Morimoto and colleagues [25], who, based on similar Dietary Reference Intake-based methods, estimated that $99 \%$ of Brazilian women at reproductive age (19-30 years) have an inadequate intake of folate. Meguid and colleagues [23] also used food frequency questionnaire to evaluate folate intake in an Egyptian case-control study focusing MTHFR $677 \mathrm{C}>\mathrm{T}$ and $1298 \mathrm{~A}>\mathrm{C}$ polymorphisms as maternal risk factors for DS. They found that $90 \%$ of case mothers had a folate intake below the Recommended Daily Allowance [11], which significantly differed from control mothers $(33 \%)$ and they also reported that $677 \mathrm{~T}$ and mainly $1298 \mathrm{C}$ contributed to DS risk.

Contrary to the study of Meguid and colleagues [23], our results suggest that folate deficiency could not be considered, by itself, as a risk factor for DS in our population, since a poor consumption of this micronutrient was found in both DS and control mothers, without significant differences. However, a significant decreased intake of methionine and zinc was verified among DS mothers in relation to controls. Although zinc intake median values in both groups were inadequate in comparison to the recommended value, methionine intake median was lower than the reference intake only among DS mothers. Both micronutrients actively participate from key steps of folate pathway. Methionine is the immediate precursor of SAM, the major intracellular methyl donor for DNA, protein and lipid methylation maintenance. After donating its methyl group, SAM is converted into S-adenosylhomocysteine (SAH), which then becomes homocysteine after losing its adenosine in a reversible manner. On the other hand, zinc is a biologically essential metal which acts in important steps of folate pathway, including the synthesis of methionine from betaine and homocysteine by betaine-homocysteine methyl transferase (BHMT), which utilizes a zinc ion to activate homocysteine, and the transfer of a methyl group from methyltetrahydrofolate to homocysteine by cobalamin-dependent methionine synthase (MetH) and cobalamin-independent methionine synthase (MetE) [21]. By this way, according to our nutritional findings, it is tempting to speculate that an inadequate consumption of methionine in DS mothers concomitantly to an environment also deficient in folate and zinc could directly or indirectly diminish the methionine pools, perturbing the production of methyl groups and leading to a greater chance of chromosomal instability and nondisjunction of chromosome 21. Therefore, the interaction between mainly zinc and folate intake remains controversial. Hong and colleagues [19] reported a reduction in plasma homocysteine and folate levels in zinc-deficient rats, presumably secondary due to an increase of hepatic methionine synthase activity. However, tissue methionine concentrations were not available and the experimental models used were extreme cases of zinc deficiency, so that it was not possible to specify what extent of alterations a mild deficiency of zinc would cause. To our knowledge, none subsequent study investigated the interference of zinc deficiency on plasma homocysteine and folate concentrations in humans and it is not clear if zinc requirements for the catalytic activity in rats could be extrapolated for humans. Additionally, although some reports also indicated a potential mutual inhibition on absorption between zinc and folate [13], several subsequent studies found no measurable effect of folic acid intake over human zinc status $[14,16]$. Of particular interest, these two latter studies $[14,16]$ were conducted among women of childbearing age, whose age range overlaps those established in our study.

A limitation of this present work, however, was the use of a food-questionnaire instead of the proper dosage of plasma homocysteine and erythrocyte folate. Of the published studies about the impact of folate gene polymorphisms on DS accomplished up to now, only eight $[2,4,10,20,22,30,31,37]$ evaluated the plasma homocysteine levels in all or part of their DS mothers. However, we should stress that although the use of biochemical dosage is undoubtedly more reliable than dietary intake-based methods, both of them could be harmed by possible changes of alimentary habits along the life, since these analyses are taken some time after the birth of a DS child.

In conclusion, there are still many divergences about the relation between chromosome 21 nondisjunction and one-carbon metabolism gene polymorphisms in different populations. Taken together, the discordant data from distinct geographic areas (in the same or in different countries) may reflect nutritional, cultural and socioeconomic heterogeneity besides variations related to genetic background, nutritional inferences and se- 
lection criteria (including mother's age at conception, sample size and differences between case and control samples). By this way, more nutrigenomics studies using large sized and well-defined matched samples of young DS mothers, as well as biochemical correlation analysis are urgently needed to clarify the role of maternal folate pathway polymorphisms and nutritional intake in DS risk. Recently, Migliore and colleagues [24] demonstrated an increased rate of chromosome 21 nondisjunction in peripheral lymphocytes of DS mothers. These findings point that nondisjunction events also occur in the somatic cells of these women, suggesting a generalized susceptibility to abnormal chromosomal segregation both in meiotic and mitotic process. Such results, combined to ours, indicate that the supplementation of folic acid and -associated micronutrients could be considered in women capable of becoming pregnant. Therefore, we should consider that while errors at maternal meiosis II occurs in the moment that precedes fertilization, trisomy 21 caused by nondisjunction at meiosis I (the predominant cause of DS) may occur since the beginning of the cellular division in the fetal ovary during the grandmother's pregnancy until the final differentiation of the primary oocyte in secondary oocyte. This aspect implicates that, probably, the benefits of folate fortification (initiated in Brazil and other countries around year 2004) in decreasing DS, probably will only be noticed in the next generation. Nevertheless, we should take care about uncontrolled population-wide interventions of folic acid, since some evidence have pointed to possible adverse effects of unmetabolized folic acid [7]. Another preoccupation is that excessive supplemental levels of folate during the pre-conceptional period could select embryos carrying polymorphic alleles and it could increase the prevalence of other human life-threatening diseases associated with these variant alleles, like some types of cancer and Alzheimer disease.

\section{Acknowledgements}

The authors thank the mothers that kindly participated in this study and the physicians who supported the recruitment efforts. This work was supported by public funds from FAPERJ (E-26/171.288/2004), CNPq and CEPUERJ.

\section{References}

[1] G.L. Acacio, R. Barini, C.S. Bertuzzo, E.C. Couto, J.M. Annichino-Bizzacchi and W.P. Junior, Methylenetetrahydrofolate reductase polymorphisms and their association with trisomy 21, Prenat Diagn 25 (2005), 1196-1199.

[2] J.M. Biselli, E.M. Goloni-Bertollo, B.L. Zampieri, R. Haddad, M.N. Eberlin and E.C. Pavarino-Bertelli, Genetic polymorphisms involved in folate metabolism and elevated plasma concentrations of homocysteine: maternal risk factors for Down syndrome in Brazil, Genet Mol Res 7 (2008), 33-42.

[3] K. Boduroglu, Y. Alanay, B. Koldan and E. Tuncbilek, Methylenetetrahydrofolate reductase polymorphisms as maternal risk for Down syndrome in Turkey, Am J Med Genet 127 (2004), 5-10.

[4] P. Bosco, R.M. Gueant-Rodriguez, G. Anello, C. Barone, F. Namour, F. Caraci, A. Romano, C. Romano and J.L. Gueant, Methionine synthase (MTR) $2756(\mathrm{~A} \rightarrow \mathrm{G})$ polymorphism, double heterozygosity methionine synthase 2756 AG/methionine synthase reductase (MTRR) 66AG, and elevated homocysteinemia are three risk factors for having a child with Down syndrome, Am J Med Genet 121 (2003), 219-224.

[5] B. Chadefaux-Vekemans, M. Coude, F. Muller, J.F. Oury, A. Chabli, J. Jais and P. Kamoun, Methylenetetrahydrofolate reductase polymorphism in the etiology of Down syndrome, Pediatr Res 51 (2002), 766-767.

[6] A. Chango, N. Fillon-Emery, C. Mircher, H. Blehaut, D. Lambert, B. Herbeth, S.J. James, M.O. Rethore and J.P. Nicolas, No association between common polymorphisms in genes of folate and homocysteine metabolism and the risk of Down's syndrome among French mothers, Br J Nutr 94 (2005), 166169.

[7] D. Charles, A.R. Ness, D. Campbell, G. Davey Smith and M.H. Hall, Taking folate in pregnancy and risk of maternal breast cancer, BMJ 329 (2004), 1375-1376.

[8] J. Chen, E. Giovannucci, K. Kelsey, E.B. Rimm, M.J. Stampfer, G.A. Colditz, D. Spiegelman, W.C. Willett and D.J. Hunter, A methylenetetrahydrofolate reductase polymorphism and the risk for colorectal cancer, Cancer Res 56 (1996), 4862-4864.

[9] F. Coppedè, G. Marini, S. Bargagna, L. Stuppia, F. Minichilli, I. Fontana, R. Colognato, G. Astrea, G. Palka and L. Migliore, Folate gene polymorphisms and the risk of Down syndrome pregnancies in young Italian women, Am J Med Genet A 140 (2006), 1083-1091.

[10] L.R. da Silva, N. Vergani, L. Galdieri, M.P. Ribeiro Porto, S.B. Longhitano, D. Brunoni, V. D'Almeida and A.B. Alvarez Perez, Relationship between polymorphisms in genes involved in homocysteine metabolism and maternal risk for Down syndrome in Brazil, Am J Med Genet 135 (2005), 263-267.

[11] Dietary Reference Intakes for thiamin, riboflavin, niacin, vitamin B6, folate, vitamin B12, pantothenic acid, biotin, and choline: a report of the Standing Committee on the Scientific Evaluation of Dietary Reference Intakes and its panel on folate, other B vitamins, and choline and subcommittee on upper reference levels of nutrients, Washington, DC: National Academy Press, 1998.

[12] T.K. Eskes, Abnormal folate metabolism in mothers with Down syndrome offspring: Review of the literature, Eur $J$ Obstet Gynecol Reprod Biol 124 (2006), 130-133.

[13] F.K. Ghishan, H.M. Said, P.C. Wilson, J.E. Murrell and H.L. Greene, Intestinal transport of zinc and folic acid: a mutual inhibitory effect, Am J Clin Nutr 43 (1986), 258-262. 
[14] T.J. Green, C.M. Skeaff, S.J. Whiting and R.S. Gibson, Effect of folic acid supplementation on plasma zinc concentrations of young women, Nutrition 19 (2003), 522-523.

[15] L.B. Grillo, G.L. Acácio, R. Barini, W. Pinto Jr and C.S. Bertuzzo, Mutações no gene da metiltetrahidrofolato redutase e síndrome de Down, Cad Saúde Pública 18 (2002), 17951797.

[16] M. Hansen, S. Samman, L.T. Madsen, M. Jensen, S.S. Sørensen and B Sandström, Folic acid enrichment of bread does not appear to affect zinc absorption in young women, $\mathrm{Am}$ J Clin Nutr 74 (2001), 125-129.

[17] C.A. Hobbs, M.A. Cleves, R.M. Lauer, T.L. Burns and S.J. James, Preferential transmission of the MTHFR 677T allele to infants with Down syndrome: implication for survival advantage, Am J Med Genet 113 (2002), 9-14.

[18] C.A. Hobbs, S.L. Sherman, P. Yi, S.E. Hopkins, C.P. Torfs, R.J. Hine, M. Pogribna, R. Rozen and S.J. James, Polymorphisms in genes involved in folate metabolism as maternal risk factors for Down syndrome, Am J Hum Genet 67 (2000), 623-630.

[19] K.H. Hong, C.L. Keen, Y. Mizuno , K.E. Johnston and T. Tamura, Effects of dietary zinc deficiency on homocysteine and folate metabolism in rats, J Nutr Biochem 11 (2000), 165169.

[20] S.J. James, M. Pogribna, I.P. Pogribny, S. Melnyk, R.J. Hine, J.B. Gibson, P. Yi, D.L. Tafoya, D.H. Swenson, V.L. Wilson and D.W. Gaylor, Abnormal folate metabolism and mutation in the methylenetetrahydrofolate reductase gene may be maternal risk factors for Down syndrome, Am J Clin Nutr 70 (1999), 495-501.

[21] M. Koutmos, R. Pejchal, T.M. Bomer, R.G. Matthews, J.L. Smith and M.L. Ludwig, Metal active site elasticity linked to activation of homocysteine in methionine synthases, Proc Nat Acad Sci USA 105 (2008), 3286-3291.

[22] M.L. Martinez-Frias, B. Perez, L.R. Desviat, M. Castro, F. Leal, L. Rodríguez, E. Mansilla, M.L. Martínez-Fernández, E. Bermejo, E. Rodríguez-Pinilla, D. Prieto and M. Ugarte, Maternal polymorphisms 677C-T and 1298A-C of MTHFR, and 66A-G MTRR genes: is there any relationship between polymorphisms of the folate pathway, maternal homocysteine levels, and the risk for having a child with Down syndrome? Am J Med Genet A 140 (2006), 987-997.

[23] N.A. Meguid, A.A. Dardir, M. Khass, L.E. Hossieny, A. Ezzat and M.K. El Awady, MTHFR genetic polymorphism as a risk factor in Egyptian mothers with Down syndrome children, Dis Markers 24 (2008), 19-26.

[24] L. Migliore, G. Boni, R. Bernardini, F. Trippi, R. Colognato, I. Fontana, F. Coppedè and I. Sbrana, Susceptibility to chromosome malsegregation in lymphocytes of women who had a Down syndrome child in young age, Neurobiol Aging $\mathbf{2 7}$ (2006), 710-716

[25] J.M. Morimoto, D.M. Marchioni and R.M. Fisberg, Using dietary reference intake-based methods to estimate prevalence of inadequate nutrient intake among female students in Brazil, $J$ Am Diet Assoc 106 (2006), 733-736.

[26] V.B. O'Leary, A. Parle-McDermott, A.M. Molloy, P.N. Kirke, Z. Johnson, M. Conley, J.M. Scott and J.L. Mills, MTRR and MTHFR polymorphism: link to Down syndrome? Am J Med Genet 107 (2002), 151-155.

[27] A. Parle-McDermott, J.L. Mills, P.N. Kirke, V.B. O'Leary, D.A. Swanson, F. Pangilinan, M. Conley, A.M. Molloy, C. Cox, J.M. Scott and L.C. Brody, Analysis of the MTHFR $1298 \mathrm{~A}>\mathrm{C}$ and $677 \mathrm{C}>\mathrm{T}$ polymorphisms as risk factors for neural tube defects, J Hum Genet 48 (2003), 190-193.
[28] A.K. Rai, S. Singh, S. Mehta, A. Kumar, L.K. Pandey and R. Raman, MTHFR C677T and A1298C polymorphisms are risk factors for Down's syndrome in Indian mothers, $J$ Hum Genet 51 (2006), 278-283.

[29] C.B. Santos-Rebouças and M.M. Pimentel, Implication of abnormal epigenetic patterns for human diseases, Eur J Hum Genet 15 (2007), 10-17.

[30] I. Scala, B. Granese, M. Sellitto, S. Salome, A. Sammartino, A. Pepe, P. Mastroiacovo, G. Sebastio and G. Andria, Analysis of seven maternal polymorphisms of genes involved in homocysteine/folate metabolism and risk of Down syndrome offspring, Genet Med 8 (2006), 409-416.

[31] J.J. Sheth and F.J. Sheth, Gene polymorphism and folate metabolism: a maternal risk factor for Down syndrome, Indian Pediatr 40 (2003), 115-123.

[32] M. Shi, D. Caprau, P. Romitti, K. Christensen and J.C. Murray, Genotype frequencies and linkage disequilibrium in the CEPH human diversity panel for variants in folate pathway genes MTHFR, MTHFD, MTRR, RFC1, and GCP2, Birth Defects Res A Clin Mol Teratol 67 (2003), 545-549.

[33] R. Sichieri, Estudo de validação do questionário de freqüencia de consumo de alimentos, Epidemiologia da obesidade, Rio de Janeiro, Brazil: EdUERJ, 1998, 25-34.

[34] R.S. Spielman, R.E. McGinnis and W.J. Ewens, Transmission test for linkage disequilibrium: the insulin gene region and insulin-dependent diabetes mellitus (IDDM), Am J Hum Genet 52 (1993), 506-516.

[35] K. Stegmann, A. Ziegler, E.T. Ngo, N. Kohlschmidt, B. Schroter, A. Ermert and M.C. Koch, Linkage disequilibrium of MTHFR genotypes $677 \mathrm{C} / \mathrm{T}-1298 \mathrm{~A} / \mathrm{C}$ in the German population and association studies in probands with neural tube defects (NTD), Am J Med Genet 87 (1999), 23-29.

[36] L. Stuppia, V. Gatta, A.R. Garpari, I. Antonucci, E. Morizio, G. Calabrese and G. Palka, $677 \mathrm{C}>\mathrm{T}$ mutation in the 5,10MTHFR gene and risk of Down syndrome in Italy, Eur J Hum Genet 10 (2002), 388-390.

[37] N. Takamura, T. Kondoh, S. Ohgi, K. Arisawa, M. Mine, S. Yamashita and K. Aoyagi, Abnormal folic acid-homocysteine metabolism as maternal risk factors for Down syndrome in Japan, Eur J Nutr 43 (2004), 285-287.

[38] N.M. van der Put, F. Gabreels, E.M. Stevens, J.A. Smeitink, F.J. Trijbels, T.K. Eskes, L.P. van den Heuvel and H.J. Blom, A second commom mutation in the methylenetetrahydrofolate reductase gene: an additional risk factor for neural-tube defects?, Am J Hum Genet 62 (1998), 1044-1051.

[39] S.S. Wang, F.Y. Qiao, L. Feng and J.J. Lv, Polymorphisms in genes involved in folate metabolism as maternal risk factors for Down syndrome in China, J Zhejiang Univ Sci B 9 (2008), 93-99.

[40] X. Wang, P. Thomas, J. Xue and M. Fenech, Folate deficiency induces aneuploidy in human lymphocytes in vitro-evidence using cytokinesis-blocked cells and probes specific for chromosomes 17 and 21, Mutat Res 551 (2004), 167-180.

[41] A. Wilson, R. Platt, Q. Wu, D. Leclerc, B. Christensen, H. Yang, R.A. Gravel and R. Rozen, A common variant in methionine synthase reductase combinated with low cobalamin (vitamin B12) increases risk for spina bifida, Mol Genet Metab 67 (1999), 317-323.

[42] E. Zintzaras, Maternal gene polymorphisms involved in folate metabolism and risk of Down syndrome offspring: a metaanalysis, J Hum Genet 52 (2007), 943-953. 


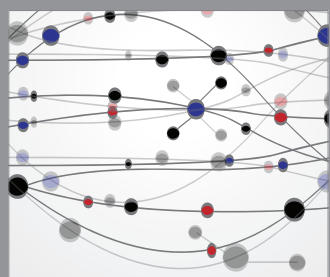

The Scientific World Journal
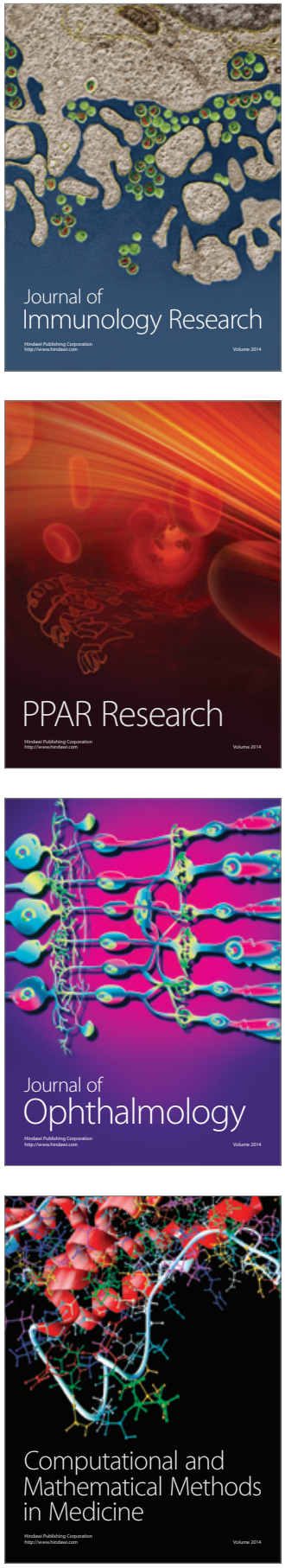

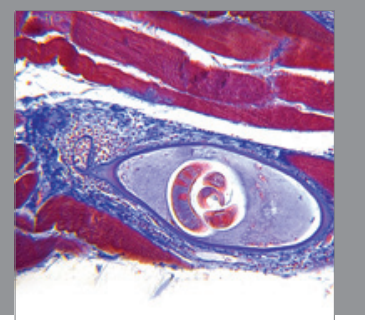

Gastroenterology

Research and Practice


\section{Hindawi}

Submit your manuscripts at

http://www.hindawi.com


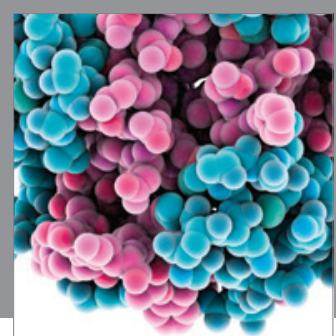

Journal of
Diabetes Research

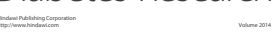

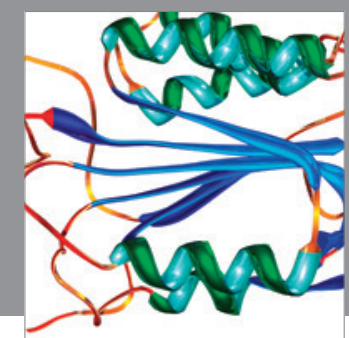

Disease Markers
